\title{
RESPONSE OF NORMAL AND MULTIPLE SCLEROTIC SUBJECTS TO TYPHOID-PARATYPHOID VACCINE INJECTIONS
}

\author{
BY
}

\author{
E. J. FIELD, C. A. GREEN, and HENRY MILLER \\ From the Royal Victoria Infirmary, Newcastle upon Tyne and the Prudhoe and \\ Monkton Hospital, Prudhoe, Northumberland
}

The suspicion that an immune reaction is involved at some stage in the pathogenesis of multiple sclerosis is implicit in much of the recent literature of the disease (Miller and Schapira, 1959). If this were so, multiple sclerotic subjects might possibly manifest an enhanced capacity to produce antibodies; or alternatively, if they are actively producing auto-antibodies, then their capacity to respond to other antigens might be diminished.

To explore these possibilities the responses of multiple sclerotic patients to the inoculation of a standard typhoid-paratyphoid vaccine (T.A.B.T., Burroughs-Wellcome) have been evaluated and compared with those in normal subjects.

\section{Method}

In this series 21 multiple sclerotics and 23 control subjects were examined. The latter were physically healthy high-grade mental defectives, actively employed, and taken to represent 'normal controls'. The patients with multiple sclerosis were in various stages of the disease but no apparent differences were noted in the responses obtained.

In each case a Widal test was carried out before the first injection to serve as a 'base-line', after which $0.5 \mathrm{ml}$. T.A.B.T. No. 1 (Wellcome) was injected into the deltoid muscle of the non-dominant arm. This No. 1 antigen is a vaccine comprising heat-killed organisms as follows:-

$$
\begin{aligned}
& \text { S. typhi } 500 \\
& \text { S. paratyphi A } 250 \text { million organisms in } 1 \mathrm{ml} \text {. } \\
& S \text {. paratyphi B } 250
\end{aligned}
$$

The first few multiple sclerosis patients were confined to bed for $\mathbf{4 8}$ hours after inoculation and their temperatures recorded four-hourly, but in the absence of any constitutional reactions this procedure was soon abandoned.

At the end of 14 days another Widal test was performed and a second intramuscular injection of antigen given, this time $1 \mathrm{ml}$. of T.A.B.T. No. 2 (Wellcome). This No. 2 antigen also comprises heat-killed organisms, but in the following amounts:-

$$
\left.\begin{array}{l}
\text { S. typhi } 1,000 \\
\text { S. paratyphi A } 500 \\
\text { S. paratyphi } B 500
\end{array}\right\} \text { million organisms in } 1 \mathrm{ml} \text {. }
$$

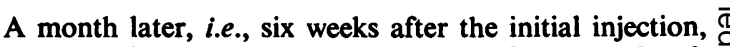
the Widal test was repeated and a further $1.0 \mathrm{ml}$. T.A.B.T. No. 2 injected. Care was taken to use the same ${ }^{\text {s }}$ batches of T.A.B.T. No. 1 and 2 for groups of controls and patients.

This procedure of Widal test followed by a further $1.0 \mathrm{ml}$. T.A.B.T. No. 2 injection was repeated monthly for six to eight months.

To meet the possibility that a short-lived response to injection might disappear within a month, and be missed + when the next Widal test was done, a subsidiary exf. periment was carried out in which Widal tests were dope $\infty$ one week (and sometimes again two weeks) aftato inoculation with T.A.B.T. No. 2. Eight multiple scleros patients and 15 controls were investigated in this wag. The results of this series are set out in Table $I$.

No therapeutic effect was noted amongst the multiple sclerotic patients, though one or two reported temporafy subjective improvement. On the other hand no untowand effects were observed in either the control or experimental group.

The Widal test (or more strictly the 'tube agglutination test') as carried out routinely in this hospital was used throughout. The antigen employed was that supplied by the Standards Laboratory of the Public Health Labora-⿳亠丷厂 tory Service. The range of serum dilutions was $1: 25$, $1: 50,1: 125,1: 250,1: 500,1: 1,000,1: 2,500$, $1: 5,000, \quad 1: 10,000, \quad 1: 20,000, \quad 1: 50,000$, and $1: 100,000$. Incubation was carried out in a water-batho for four hours at $50^{\circ} \mathrm{C}$., the tubes being stored overnight ${ }^{3}$ and read the next morning after having remained at room temperature for $\mathbf{3 0}$ minutes.

\section{Results}

In assessing the results of the short-term experiment presented in Table $I$, only a difference of titre of at least two tubes in the Widal test has? been accepted as significant, since a rise of one tube may possibly fall within the range of experimentab error. The cases listed had no demonstrable TO antibodies before the relevant injection, so the elevations shown are from a zero base-line. Sinces all these subjects had been previously injected several times at monthly intervals, it is a secondary 
TABLE I

RESPONSES ONE WEEK AFTER RE-INOCULATION WITH T.A.B.T. No. 2

\begin{tabular}{|c|c|c|c|}
\hline \multicolumn{4}{|c|}{ No. of Tubes Showing Increase in Titre } \\
\hline \multicolumn{2}{|l|}{ Controls } & \multicolumn{2}{|c|}{ Mutiple Sclerosis } \\
\hline $\begin{array}{l}\text { E.A.H. } \\
\text { L.A.H. } \\
\text { J.Q. } \\
\text { T.M. } \\
\text { T.H. } \\
\text { E.K. } \\
\text { G.W.S. } \\
\text { D.P. } \\
\text { R.H. } \\
\text { S.B. } \\
\text { E.W.B. } \\
\text { G.F.L. } \\
\text { E.B.B. } \\
\text { E.J.P. } \\
\text { G.D. }\end{array}$ & $\begin{array}{r}3 \\
3 \\
2 \\
\frac{6}{3} \\
\frac{3}{3} \\
\frac{2}{3}\end{array}$ & $\begin{array}{l}\text { R.G. } \\
\text { B.S. } \\
\text { A.L. } \\
\text { P.S. } \\
\text { E.M. } \\
\text { E.F. } \\
\text { E.D. } \\
\text { E.J.F. }\end{array}$ & $\begin{array}{l}= \\
= \\
= \\
=\end{array}$ \\
\hline
\end{tabular}

If a two-tube rise from the zero base-line is accepted as certainly positive, then $x^{2}$ (with Yates' correction) $=4.518$ and $P=0.02$. There is less than one chance in $\mathbf{5 0 0}$ that this difference is coincidental.

response which is being assessed. Under these conditions analysis shows a significantly greater response by control subjects than by multiple sclerosis cases. The changes in $\mathrm{BO}$ agglutinins were not significant, nor were those in any of the other titres which were examined.

The long-term experiments indicated that the difference between control and multiple sclerosis cases noted above was a transient phenomenon, and that in both groups repeated monthly inoculations produced a variable and uniformly ill-sustained response in all $O$ titres.

To the question propounded in the introduction to this paper it seems possible to give a definite answer. Established cases of multiple sclerosis show a diminished immediate TO response as compared with normal subjects. On the other hand no differences are found during a subsequent period of six months or more. The incidental finding that normal subjects manifest only a moderate response, which may level off or prove poorly sustained, was unexpected after such intensive administration of vaccine.

(Considerations of space prevent the publication of detailed protocols. Records of antibody responses extending in some cases up to 10 months are available and would be gladly supplied to anyone wishing for detailed information.)

\section{Discussion}

The main object of this study was to investigate the immune response in multiple sclerosis, and from this point of view it would appear that sufferers from this disease react less vigorously to TO antigen than do control cases. The significance of this empirical finding will be evident only when information is available about the response encountered in patients with other nervous disorders causing comparable grades of 'debility': no difference related to the degree of disablement was noted in the present study.

Of four sisters, E.B., E.J.P., E.M., and P.S., E.B. and P.S. are uniovular twins. P.S. and E.M. suffer respectively from advanced and mild multiple sclerosis. Neither of the multiple sclerotic sisters nor the normal sister E.J.P. responded to TO antigen at one week, but E.B., the unaffected identical twin of the advanced case, responded normally. This finding does not suggest a familial tendency to react unusually, but further experiments, preferably employing the response to immunization against tetanus, might furnish further information on this point.

Surprisingly, no long-term observations of the kind we have made appear to have been reported. Failure of somatic antibodies to appear after prophylactic T.A.B. vaccination has been recorded by a number of workers (Stuart and Krikorian, 1928; Felix, 1924; Gardner, 1929).

Isolated tests made some time after vaccination have, however, suggested that responses were not very well sustained (Wilson, 1945).

The absence of any prolonged boosting effect was an unexpected finding, which re-opens once more the issue of the efficacy of routine T.A.B.T. prophylaxis, recently also called into question by the careful field studies of Cvjetnovic (1957). For historical reasons this method of protection has never been subjected to controlled trial, and personal enquiry amongst those best qualified to judge reveals considerable scepticism as to its practical value.

\section{Summary}

Multiple sclerotic patients produce less TO antibodies in response to a booster inoculation of T.A.B.T. No. 2 (Wellcome) than do control subjects.

Neither multiple sclerotic patients nor controls show a sustained $O$ response, even when monthly injections are repeated on eight occasions.

We should like to thank Dr. G. McCoull, o.B.E., Prudhoe and Monkton Hospital, and Dr. T. H. Bates, Hunter's Moor Hospital, for their cooperation in making suitable subjects available for this investigation. The assistance of the technical staff of the Department of Bacteriology, and in particular of Mr. E. C. Elliott, F.I.M.L.T., is also gratefully acknowledged.

\section{REFERENCES}

Cvjetnović, B. B. (1957). Amer. J. publ. Hlth, 47, 578.

Felix, A. (1924). J. Immunol., 9, 115.

Gardner, A. D. (1929). J. Hyg. (Camb.), 28, 376

Miller, H. G., and Schapira, K. (1959). Brit. med. J., 1, 737 and 811.

Stuart, G., and Krikorian. K. S. (1928), J. Hyg. (Camb.), 28, 105.

Wilson, J' F. (1945). Ibid., 44, 129. 